\title{
Computational modeling of blood flow in the aorta-insights into eccentric dilatation of the ascending aorta after surgery for coarctation
}

\author{
Marcela Szopos, PhD, ${ }^{a}$ Nicole Poussineau, $\mathrm{PhD},{ }^{\mathrm{b}}$ Yvon Maday, $\mathrm{PhD},{ }^{\mathrm{b}, \mathrm{c}}$ Carla Canniffe, MD, ${ }^{\mathrm{d}}$ \\ David S. Celermajer, MBBS, PhD, FRACP, ${ }^{\mathrm{e}}$ Damien Bonnet, MD, PhD, ${ }^{f}$ and Phalla Ou, MD, PhD ${ }^{d, g}$
}

\begin{abstract}
Objective: To assess whether combining a computational modeling technique with data from patient magnetic resonance imaging studies can detect different fluid dynamics and vascular biomechanical properties of the ascending and horizontal aorta in patients with angulated "gothic" arch geometry compared with those with normal "Romanesque" arch geometry after aortic coarctation repair.
\end{abstract}

\begin{abstract}
Methods: Advanced computational fluid dynamics techniques (coupled Navier-Stokes and elastodynamics equations) were used to predict the fluid-wall interactions in large arteries. We modeled the fluid dynamics and shear stress in the ascending and horizontal aorta in cases of "gothic" arch and normal "Romanesque" aortic arch geometry. A total of 30 patients after aortic coarctation repair prospectively underwent 3-dimensional magnetic resonance imaging angiography of the thoracic aorta. Measurements of the ascending and horizontal aorta were assessed using multiplanar reformatting images.
\end{abstract}

Results: Our computational model demonstrated that wall shear stress is greater in those with an angulated "gothic" aortic arch than in those with a "Romanesque" arch. In particular, wall shear stress affected the anterior and posterior segments of the ascending aorta and the inferior and superior segments of the horizontal aorta (vs the left and right segments). In vivo, a "gothic" arch was associated with dilatation of the ascending and horizontal aorta, which was eccentric rather than concentric $(P<.05)$.

Conclusions: Our results have shown that wall shear stress is eccentric and significantly increased in the ascending and horizontal aorta in patients with a "gothic" aortic arch after repair of coarctation. This suggests that patients with an angulated "gothic" aortic arch might warrant increased surveillance for aortic complications. (J Thorac Cardiovasc Surg 2014;148:1572-82)

Despite anatomically successful repair of aortic coarctation, a series of mechanical complications have been reported during medium- and long-term follow-up. These included pressure overload proximal to the site of coarctation repair, the consequences of which appear to include left ventricular

From the Université de Strasbourg, ${ }^{\text {a }}$ Institut de Recherche Mathématique Avancée, Unité Mixte De Recherche 7501, Strasbourg, France; Université Pierre et Marie Curie-Paris 6, ${ }^{\mathrm{b}}$ Faculté de Mathématiques, Unité Mixte De Recherche 7598, Laboratoire JL Lions, Paris, France; Division of Applied Mathematics, ${ }^{c}$ Brown University, Providence, Rhode Island; Department of Radiology, ${ }^{\mathrm{d}}$ University Paris Descartes, Hopital Bichat, Assistance Publique - Hôpitaux de Paris, Paris, France; Department of Medicine, ${ }^{\mathrm{e}}$ University of Sydney, Sydney, Australia; University Paris Descartes, ${ }^{\mathrm{f}}$ Hopital Necker-Enfants Malades, Assistance Publique - Hôpitaux de Paris, Paris, France; and University Paris Descartes, ${ }^{\mathrm{g}}$ Laboratoire MAP5, Unité Mixte De Recherche 8145, Paris, France.

The present study was supported by a grant from the Fédération Française de Cardiologie (France) and from the Fondation Wyeth pour la Santé de l'Enfant et de l'Adolescent (France). Dr Szopos was the recipient of a grant from the Fondation Lefoulon Delalande.

Disclosures: Authors have nothing to disclose with regard to commercial support.

Received for publication Aug 22, 2013; revisions received Nov 1, 2013; accepted for publication Nov 15, 2013; available ahead of print Feb 9, 2014.

Address for reprints: Phalla Ou, MD, PhD, Department of Radiology, Hôpital Bichat Claude Bernard, 46 rue Henri Huchard, Paris 75018, France (E-mail: phalla.ou@ bch.aphp.fr).

0022-5223/ $\$ 36.00$

Copyright (c) 2014 by The American Association for Thoracic Surgery

http://dx.doi.org/10.1016/j.jtcvs.2013.11.055 hypertrophy, ascending aortic dilatation, and upper body hypertension. ${ }^{1-4}$

Several recent studies $^{5-7}$ have proposed a coupled computational and imaging technique to increase the understanding of coarctation-induced abnormal hemodynamics and vascular biomechanics. Although several publications have validated the use of such models to assess the blood flow in the aorta, to the best of our knowledge, few studies have explored the use of such a model in patients with an abnormal aortic arch shape after coarctation repair. ${ }^{8}$ Studies reporting on the findings of various imaging techniques for those after coarctation repair have tended to be limited by heterogeneity and small patient numbers. The interpretation has been further complicated by the frequent coexistence of a bicuspid aortic valve (in $50 \%-80 \%$ of coarctation cases), which can, in turn, be associated with changes in the histologic findings of the ascending aorta that predispose to local dilatation. .,10 $^{-10}$

Two major patterns of aortic arch geometry after aortic coarctation repair have been reported: a "gothic" (acutely angulated, height-to-width ratio $>0.8$ ) and a "Romanesque" (rounded arch, no acute angle, height-to-width ratio < 0.8 ) arch. ${ }^{1,2,8,11,12}$ Our present approach has been to quantify and characterize, in a rigorous manner, the major effect of 


$$
\begin{aligned}
& \text { Abbreviations and Acronyms } \\
& \begin{aligned}
\text { 3D } & =3 \text {-dimensional } \\
\mathrm{MRI} & =\text { magnetic resonance imaging } \\
\mathrm{OFI} & =\text { oscillatory flow index } \\
\mathrm{T} & =\text { time } \\
\mathrm{Tf} & =\text { final time } \\
\mathrm{WSS} & =\text { wall shear stress }
\end{aligned}
\end{aligned}
$$

the geometric factor that leads to abnormal blood flow patterns and modified indexes of wall shear stress using computational fluid dynamics techniques and incorporating, in particular, vessel compliance. The latter consideration is known to be a key factor for providing more realistic values for indexes of wall shear stress compared with simulations assuming rigid wall behavior. ${ }^{13,14}$

The purpose of our study was to assess whether combining a computational modeling technique with data from human magnetic resonance imaging (MRI) studies could detect the different fluid dynamics and vascular biomechanics of the ascending and horizontal aorta in patients with angulated "gothic" arch geometry compared with those with normal "Romanesque" aortic geometry after aortic coarctation repair.

\section{METHODS}

We conducted 2 complementary studies: 3-dimensional (3D)-MRI angiography of the aorta in 30 patients after coarctation repair and a computational model to characterize the physical forces in the aorta (flow, pressure, and wall shear stress).

\section{MRI Study}

At our institution, patients surviving the surgical correction for coarctation of the aorta undergo routine MRI with gadolinium-enhanced 3D angiography of the aorta for clinical purposes every 1 to 2 years. All patients or their guardians provided informed consent. From January 2 to December 31,2011 , we consecutively included 30 patients who had undergone early ( $<1$ year old) surgical correction for coarctation by simple end-to-end anastomosis. Patients with any suspicion of a bicuspid or pseudo-bicuspid aortic valve on MRI were excluded. All the patients were normotensive and had an anatomically successful repair, without significant residual aortic narrowing. The right arm-leg systolic blood pressure gradient at rest was $<15 \mathrm{~mm} \mathrm{Hg}$; the continuous Doppler velocity was $<2.5 \mathrm{~m} / \mathrm{s}$, with an absence of diastolic extension of flow on the Doppler trace; and residual stenosis was absent at the coarctectomy site on MRI $(<30 \%$ residual stenosis $=100 \times[1-($ diameter at the anastomosis/diameter of the descending aorta, $10 \mathrm{~cm}$ distal to the anastomosis)]). ${ }^{1}$

All examinations were performed using a 1.5 T MRI system (Discover MR450, GE Healthcare, Milwaukee, Wis). A 32-element, cardiac, phasearray coil was used for signal acquisition. At the beginning of the examination, scout images were obtained in the axial, coronal, and sagittal orientation. Contrast-enhanced MRI-3D angiography of the aortic arch was acquired during the end-inspiratory breath hold in the oblique sagittal plane after automatic injection of gadoteric acid (Dotarem, Guerbet, Villepint, France) at a dose of $0.1 \mathrm{mmol} / \mathrm{kg}$ body weight.

The aortic arch anatomy and measurements were assessed using multiplanar reformatting images. The geometry of the aortic arch was characterized in a left anterior oblique projection, allowing the distinction between the normal and "gothic" arch, as previously described. ${ }^{1,8,11,12}$ The maximum aortic lumen area and the diameters of the ascending and horizontal aorta were measured. For each level, 2 measurements were done: the anteroposterior diameter and the left-right diameter for the ascending aorta at the level of the pulmonary artery bifurcation, the superoinferior diameter and the left-right diameter for the horizontal aorta between the right and left carotid arteries (Figures 1 and 2).

The MRI data were analyzed using the JMP software, version 5.0.1 (SAS Institute, Cary, NC). The data are presented as the mean \pm standard deviation, range, and median. Univariate comparisons of continuous variables between the normal and gothic arch groups were performed using the Student $t$ test.

\section{Computational Modeling of the Aorta}

Two interrelated mathematical models were used: one for the blood and one for the vessel wall. Blood was considered an incompressible, homogeneous, newtonian fluid. Its behavior has been described by the NavierStokes equations, ${ }^{15}$ with the unknowns being the velocity and pressure fields. This model has been shown to be valid in large arteries. ${ }^{16,17}$ The vessel wall has a complex structure ${ }^{17}$; as a first approximation, we assumed that this could be modeled as a homogeneous, isotropic, Saint-Venant Kirchhoff hyperelastic material and described by the linear elasticity equations. ${ }^{18}$ Taking into account the elastic behavior of the wall will lead to a fluid-solid interaction: the blood equations are defined on a domain that changes in time, depending on the position of the vessel wall. The vessel wall also reacts to the pressure applied by the fluid on its surface.

We discretized the Navier-Stokes equations using finite elements method and an arbitrary lagrangian-eulerian formulation, as previously described. ${ }^{15}$ For the solid equations, a finite element method was also used. ${ }^{18}$ The chosen coupling strategy is an implicit one (see Fernández and Moubachir ${ }^{19}$ or Fernández and Gerbeau ${ }^{20}$ for a thorough analysis of the accuracy of the numeric method). Discretized equations were solved using the open-source finite elements $\mathrm{C}++$ library LifeV (available at: www.lifev.org).

The geometric model of the aorta was based on 2 general patterns of aortic arch geometry previously described after successful coarctation repair: gothic (acutely angulated, height-to-width ratio $>0.8$ ) and Romanesque (rounded arch, no acute angle, height-to-width ratio $<0.8) .{ }^{1,2}$ Because our model used "ideal" geometries, we focused on reproducing these 2 different aortic arch shapes, without considering patient-specific characteristics, such as vessel radius changes. The numeric values were chosen as follows: constant radius vessel $\mathrm{R}=0.5 \mathrm{~cm}$ and constant vessel wall thickness of 0.1 $\mathrm{cm} .{ }^{20}$ We generated computational meshes of these idealized geometries using the open-source code Modulef (available at: www.rocq.inria.fr/modulef), which were then used in the input of our finite element code.

The fluid-solid model depends on several physical parameters. We chose values considered realistic in the context of blood flow ${ }^{19,20}$ : fluid viscosity, $\mu=0.003 \mathrm{~Pa} \cdot \mathrm{s}$; fluid density, $\rho_{1}=1 \mathrm{~g} / \mathrm{cm}^{3}$; Young modulus, $\mathrm{E}=3 \cdot 10^{6}$ dynes $/ \mathrm{cm}^{2}\left(1 \mathrm{dyne} / \mathrm{cm}^{2}=0.1 \mathrm{~Pa}\right) ;$ Poisson coefficient $=0.3$; and density of the structure, $\rho_{2}=1.2 \mathrm{~g} / \mathrm{cm}^{3}$.

Numeric simulations were successfully performed for the 2 geometries presented in Figure 3, using couple slices of MRI-2-dimensional cine phase-contrast data to more precisely match the model to the in vivo settings. A small time step ( 0.0001 second) was chosen to adequately resolve the complex flow features. Both systems, the fluid and structure, were initially at rest. The structure was fixed in time and space at the inlet and the outlet. An overpressure of $1.3332 \cdot 10^{4}$ dynes $/ \mathrm{cm}^{2}$ was applied at the initial section of the ascending aorta for $3 \cdot 10^{-3}$ seconds. ${ }^{15}$ This condition can be considered a rough model for flow in the aortic arch at the start of systole. ${ }^{21}$ A standard free outlet boundary condition for the fluid was imposed in the model..$^{20}$

The outcome of each simulation was the pressure and velocity field for the fluid and the displacement and velocity field of the structure at each point of the aorta, for all time $t$ between 0 and the final time (Tf) of the simulation. The $\mathrm{Tf}$ of the simulation was defined as the time when the pressure wave reached the outlet section. The time was $\mathrm{Tf}=0.025$ second for 

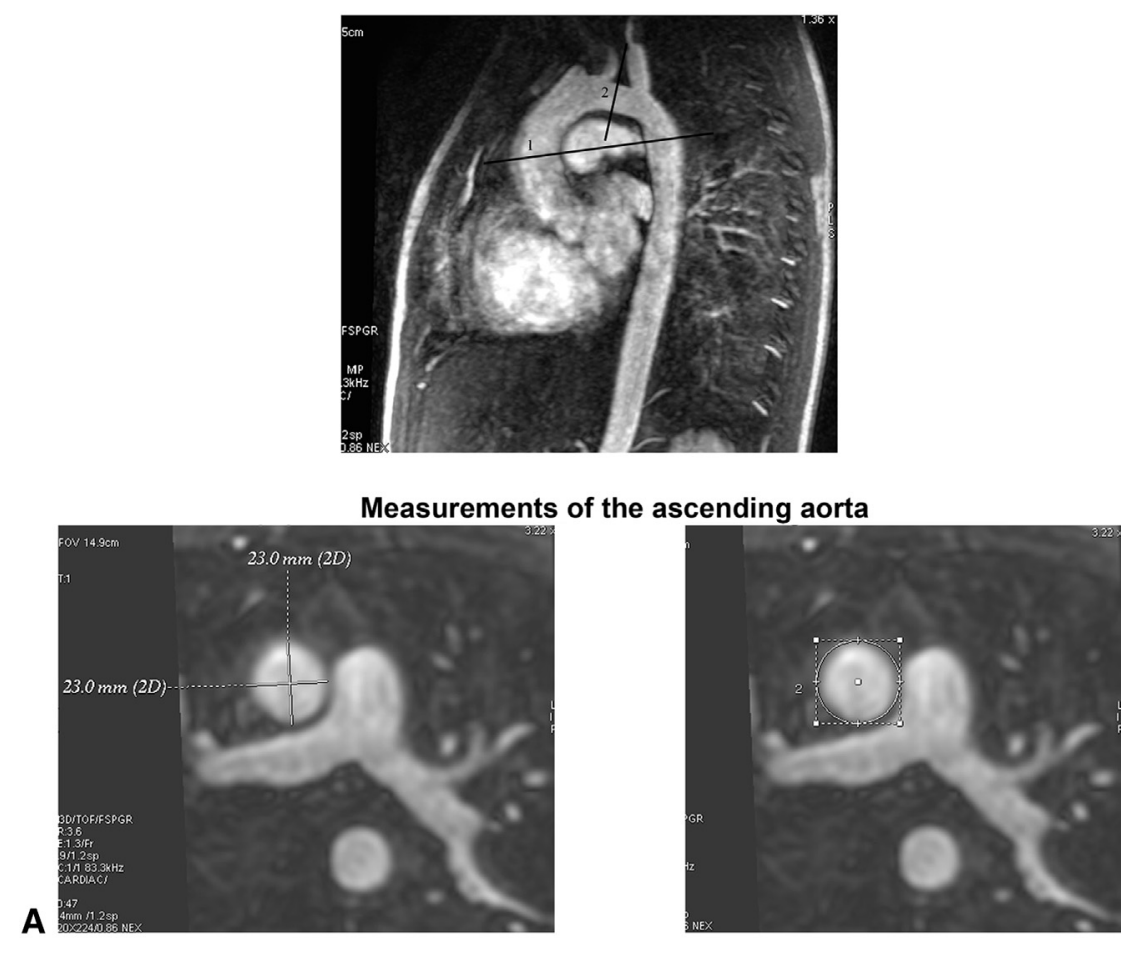

Measurements of the horizontal aorta

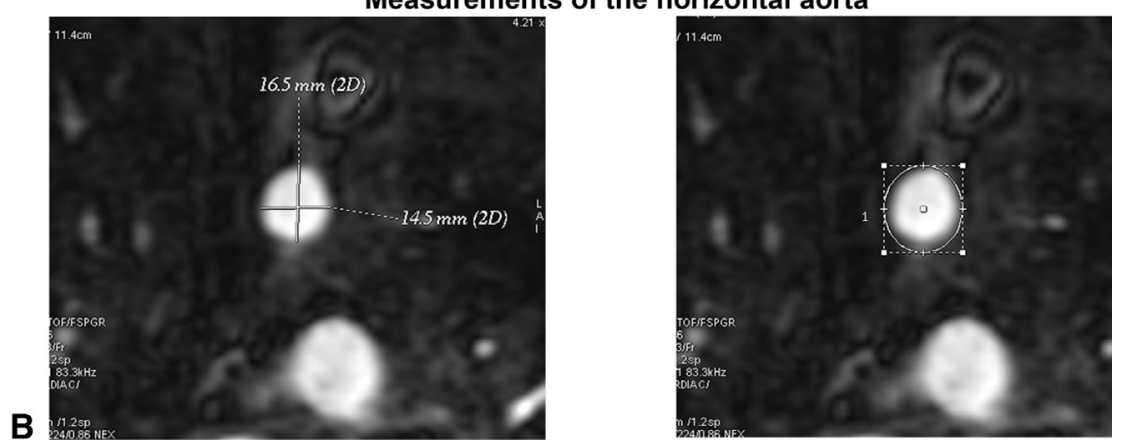

FIGURE 1. Postgadolinium magnetic resonance imaging 3-dimensional angiogram of the normal arch after coarctation repair. A, Cross-section measurements of the ascending aorta at the level of the pulmonary bifurcation (through line 1). Left, measurements of the 2 diameters (ie, anteroposterior diameter and left to right diameter) of the ascending aorta. Right, measurements of the corresponding area. B, Cross-section measurements of the horizontal aorta (through line 2). Left, Measurements of the 2 diameters (ie, superoinferior diameter and left to right diameter) of the horizontal aorta. Right, Measurements of the corresponding area.

the normal form and $\mathrm{Tf}=0.02$ second for the "gothic" form, because the "gothic" aorta is slightly shorter. The following data were extracted from the numeric simulations: the velocity vector distribution at different points of the lumen and the streamline pattern and flow rate evolution in time, calculated at the inlet and outlet sections, using the section area and velocity field. The oscillatory flow index (OFI) was also computed at the inlet section, for $\mathrm{T}=0.015$ second, as previously proposed ${ }^{22}$ :

$$
O F I=\frac{1}{2}\left(\frac{\int_{0}^{T} Q d t}{1-T}\right)
$$

where Q stands for the flow rate. An OFI of 0 corresponds to a positive flow rate throughout the vessel and a positive value to flow reversal. The percentage of reflux was calculated as a percentage, according to the difference in the maximum amplitude between the flow rate in the ascending (A) and that in the descending (D) aorta:

$$
P R=\frac{[\operatorname{maxA}(\text { gothic arch })-\max D(\text { gothic arch })]-}{[\operatorname{maxA}(\text { normal } \operatorname{arch})-\max D(\text { normal } \operatorname{arch})]}
$$

The maximum values were extracted from the data shown in Figure 4.

The pressure field was analyzed using both the spatial distribution at a precise instant and the evolution against time at some given points. The wall shear stress was defined as the tangential force per unit area exerted on a blood vessel wall as a result of flowing blood. A computational analysis of the wall shear stress was performed using the velocity variations near the vessel wall. ${ }^{22}$ 


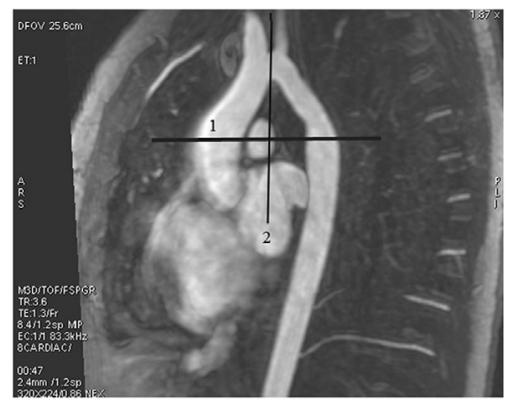

Measurements of the ascending aorta
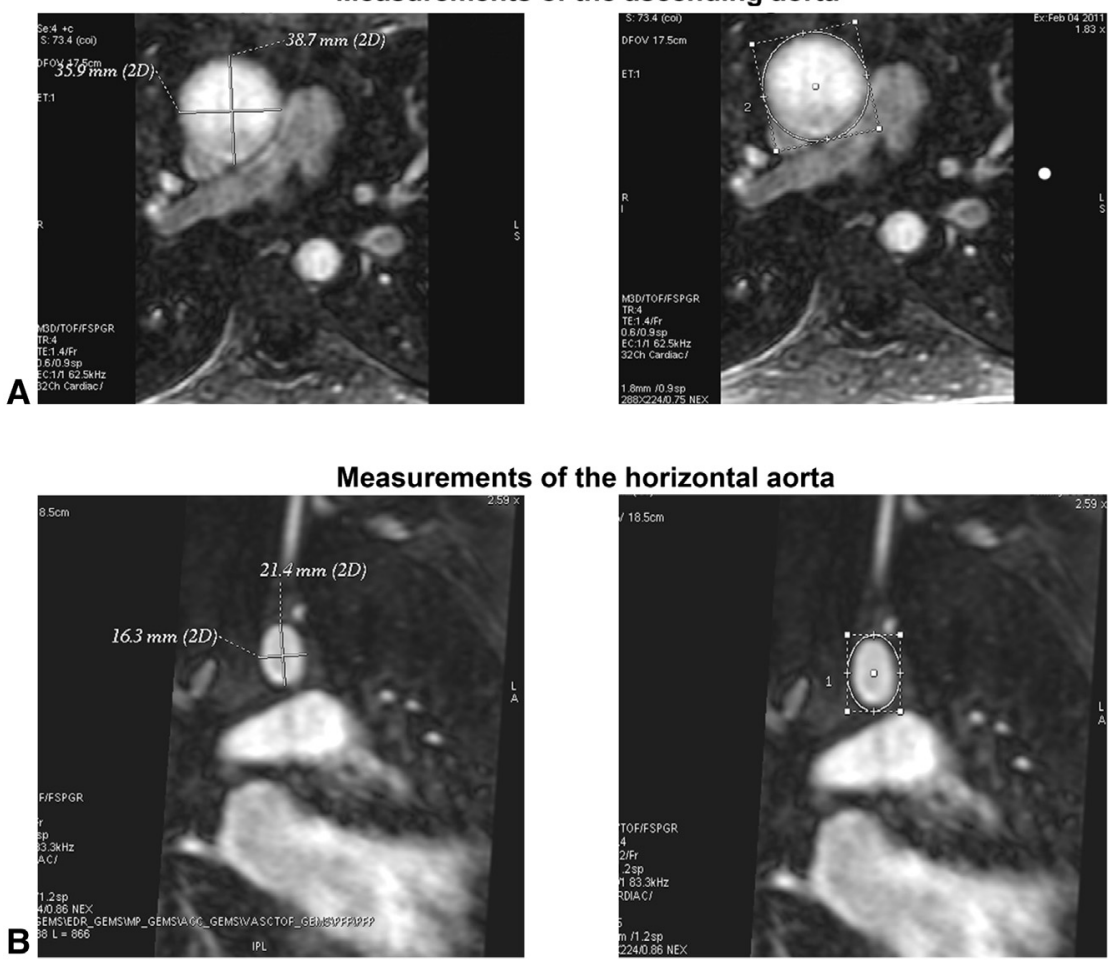

FIGURE 2. Postgadolinium magnetic resonance imaging 3-dimensional angiogram of the gothic arch after coarctation repair. A, Cross-section measurements of the ascending aorta at the level of the pulmonary bifurcation (through line 1). Left, Measurements of the 2 diameters (ie, anteroposterior diameter and left-right diameter) of the ascending aorta. Right, Measurements of the corresponding area. B, Cross-section measurements of the horizontal aorta (through line 2). Left, Measurements of the 2 diameters (ie, superoinferior diameter and left- to right diameter) of the horizontal aorta. Right, Measurements of the corresponding area.

\section{RESULTS \\ Patient Characteristics}

The patients were aged $15 \pm 5.1$ years, and their demographic characteristics are listed in Table 1.

\section{MRI Results}

The diameters and areas of the aorta were significantly increased in the "gothic" arch compared with those in the Romanesque arch. The dilatation was eccentric at the ascending and horizontal aorta. The maximal diameter was at the anteroposterior length at the ascending aorta at the level of the pulmonary artery bifurcation and in the superoinferior length at the horizontal aorta between the right and left carotid arteries (Table 1).

\section{Computational Modeling Results}

The results have been described at a particular time (T) point, that at which the pressure wave reached the descending aorta $(\mathrm{T} \approx 0.016$ second $)$.

For the velocity fields (Figure 5, $A$ and $C$ ), each vector points in the direction of the flow and its length is proportional to the velocity magnitude. The streamlines (Figure 5, $B$ and $D$ ) show another representation, in which each line is tangential to the fluid displacement. 




FIGURE 3. Aortic arch geometries showing 2 idealized geometries, corresponding to 2 extreme morphologies of the aortic arch after coarctation repair. Left, Normal arch. Right, Gothic arch.

Straight lines represent laminar flow and circles, recirculation.

We have demonstrated that geometric changes in the aortic arch shape will lead to an alteration of the local fluid dynamics in the ascending aorta. The velocity field of the normal arch will be directed from the heart toward the body; however, with an angulated "gothic" arch, the velocity field will also contains vectors directed backward (Figure 5, $A$ and $C$ ). The same behavior can be found when plotting the streamlines of flow along which the fluid particles move (Figure 5, $B$ and $D$ ). Two recirculation zones will develop in the ascending part of the "gothic" arch and will significantly correlate with the disturbed flow described by the velocity field.

The flow waves were analyzed in the ascending and descending aorta (Figure 4). The results showed a smooth flow rate curve in the normal case for the ascending aorta compared with a more irregular, oscillatory flow rate curve for the "gothic" case. The value of the OFI was equal to 0 for the normal arch, consistent with positive flow throughout the vessel. In contrast, the OFI was positive for the "gothic" arch, showing the presence of reversed flow. The percentage of reflux corresponding to the numeric simulation was $18.2 \%$.

The analysis of the pressure field showed a normal forward pressure wave in the normal arch, but both forward and reflection waves were abnormally observed in the ascending aortic of the "gothic" arch. Such forward and reflection waves generated 2 pressure peaks in the "gothic" arch (Figure 6).

The wall shear stress (WSS) was significantly greater in the "gothic" arch than in the normal arch. The differences in the WSS will affect the anterior and posterior segments of the ascending aorta and the inferior and superior segments of the horizontal aorta (compared with the left and right segments). Moreover, the WSS curves showed only 1 peak in the normal arch but 2 peaks in the "gothic" arch, corresponding to the forward and reflection wave, respectively (Figure 7).

\section{DISCUSSION}

Although studies to date have provided several interesting findings regarding the hemodynamics after coarctation repair, they did not focus on the effect of the aortic arch geometry on the blood flow and vascular properties. In the present investigation, we have provided novel information about the abnormal patterns of flow, pressure, and WSS that likely affect the thoracic aorta after surgical repair of aortic coarctation. These abnormal patterns were demonstrated in those with a "gothic" aortic arch and not in those with a normal "Romanesque" arch. In the computational model, the WSS was significantly greater in those with a "gothic" arch, affecting, in particular, the anterior and posterior segments of the ascending aorta and inferior and

\section{Normal arch}

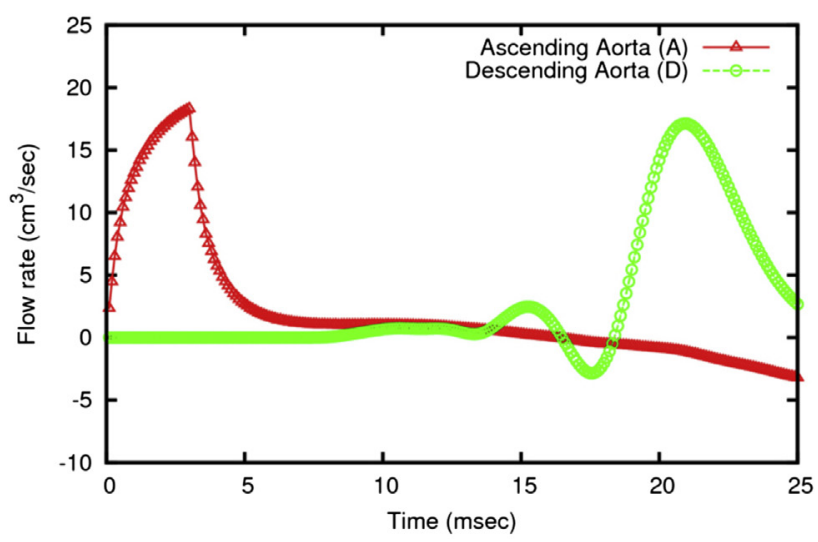

Gothic arch



FIGURE 4. Graph showing flow rate calculation plotted against time in the ascending aorta (red line) and descending aorta (green line). Note the reverse flow in the gothic arch in late systole (black arrow). 
TABLE 1. Thoracic aorta measurements

\begin{tabular}{|c|c|c|c|}
\hline Variable & $\begin{array}{l}\text { Gothic } \\
\text { arch }\end{array}$ & $\begin{array}{c}\text { Romanesque } \\
\text { arch }\end{array}$ & $\begin{array}{c}P \\
\text { value }\end{array}$ \\
\hline Patients (n) & 13 & 17 & - \\
\hline Gender & & & - \\
\hline Male & 7 & 8 & \\
\hline Female & 6 & 9 & \\
\hline Age (y) & & & .6 \\
\hline Mean \pm standard deviation & $15.9 \pm 4.9$ & $15.4 \pm 5.3$ & \\
\hline Range & $8.7-28$ & $8.2-29$ & \\
\hline Median & 14 & 14 & \\
\hline Age at operation (mo) & & & .5 \\
\hline Mean \pm standard deviation & $0.3 \pm 0.5$ & $0.3 \pm 0.6$ & \\
\hline Range & $0.1-115$ & $0.17-119$ & \\
\hline Median & 0.2 & 0.28 & \\
\hline \multicolumn{4}{|l|}{ Blood pressure at rest $(\mathrm{mm} \mathrm{Hg})$} \\
\hline Systolic & & & .04 \\
\hline Mean \pm standard deviation & $125.7 \pm 10.2$ & $113 \pm 11$ & \\
\hline Range & $98-136$ & $95-128$ & \\
\hline Median & 125 & 114 & \\
\hline Diastolic & & & .1 \\
\hline Mean \pm standard deviation & $69 \pm 8.2$ & $67 \pm 5.9$ & \\
\hline Range & $48-76$ & $49-77$ & \\
\hline Median & 68 & 67 & \\
\hline \multicolumn{4}{|l|}{ Ascending aorta } \\
\hline Anteroposterior diameter $(\mathrm{mm})$ & $34.3 \pm 3.5$ & $21.9 \pm 3.8$ & $<.005$ \\
\hline Right-left diameter (mm) & $27.3 \pm 5.2$ & $21.8 \pm 3.9$ & .2 \\
\hline Area $\left(\mathrm{mm}^{2}\right)$ & $920.4 \pm 283.1$ & $454.5 \pm 158.7$ & $<.001$ \\
\hline \multicolumn{4}{|l|}{ Horizontal aorta } \\
\hline Superoinferior diameter $(\mathrm{mm})$ & $23.3 \pm 2.4$ & $14.2 \pm 2.4$ & $<.005$ \\
\hline Right-left (mm) & $19.3 \pm 2.1$ & $13.8 \pm 2.4$ & .1 \\
\hline Area $\left(\mathrm{mm}^{2}\right)$ & $452.2 \pm 6.4$ & $191.3 \pm 62.2$ & $<.001$ \\
\hline
\end{tabular}

Diameter and area measurements at the level of the ascending and horizontal aorta determined from 3D-MRI angiogram of the thoracic aorta in patients presenting with a "gothic ach" versus a "Romanesque arch."

superior segments of the horizontal aorta (compared with the left and right segments). Using 3D-MRI angiography, we also documented that "gothic" arch is associated with dilatation that is eccentric rather than concentric.

The findings from the present study have demonstrated that a "gothic" arch geometry leads to an abnormal reflection of the systolic wave, which then induces greater systolic pressure and perturbed wall shear proximally. As previously assessed, ${ }^{23-25}$ WSS represents an important force that plays a significant role in endothelial damage and plaque formation at different privileged locations (eg, carotid bifurcation). Although the effect of WSS alterations on the exposed aorta is still not fully understood, recent studies have provided evidence to suggest a relationship between the WSS changes and vascular modifications, such as aortic dilatation. ${ }^{26,27}$ Our study also found a positive correlation between the perturbations of the flow dynamics demonstrated by the computational models and the aortic dilatation demonstrated by 3D-MRI angiography. We have observed only 1 point to assess the mechanism of aortic dilatation. Therefore, we could not comment on the causal effect of increased WSS and/or abnormal flow on the development of dilatation. Aortic dilatation could also result from the native abnormal wall properties of the aorta in patients with a "gothic" arch; thus, the greater WSS would be the effect and not the cause of the aortic dilatation. ${ }^{9}$ Additional prospective series are mandatory to assess the postoperative evolution of the aortic arch anatomy. Additional clinical studies using MRI-4-dimensional time-resolved flow data would also be helpful for a comprehensive assessment of the 3-directional blood flow velocities in the setting of such abnormal aortic arch geometry associated with complex flow patterns. ${ }^{28}$

Increased stiffness and decreased compliance of the central aorta have previously been shown in the "gothic" arch. ${ }^{29}$ In the presence of increased wave reflection, the afterload of the left ventricle will be increased and, consequently, will lead to left ventricular hypertrophy. This likely explains the high prevalence of an increased left ventricular mass in such patients after coarctectomy, as previously reported. ${ }^{30}$

Our computational model involved several simplifications and assumptions about the geometry and physical parameters. Nevertheless, the description of the main features of blood flow was in good qualitative agreement with that from previously reported studies, ${ }^{31}$ in which the vessel dynamics were acquired using MRI techniques and not simulated in interaction with the hemodynamics, such as in the present study. The comparison between our computational data and the 3D-MRI imaging data showed that they are in good accordance (eg, the computed percentage of reflux was in agreement with the experimental results previously reported in an in vivo $\operatorname{study}^{30}$ ). The main difference in the flow rate curves was that for the 3D-MRI results, an additional loss of energy resulted from blood going into the head and neck vessels, which were not included in our models.

\section{Limitations of the Mathematical Model}

In the computational modeling arm of the present study, we selected 2 idealized shapes for the aorta, rather than studying a variety of shapes and angulations. Furthermore, we did not represent the right innominate, left common carotid, and left subclavian arteries. This is an important limitation, because our mathematical models were derived from nonpatient-specific data. The flow and time-varying changes in the aortic diameter derived from the entire $30 \mathrm{pa}-$ tients' MRI data would have provided more realistic values for the computational fluid dynamics. In addition, a model derived from patient-specific data would have included the anastomotic site, which will usually be less compliant than the normal aorta and, thus, could, itself, contribute to the abnormal flow dynamics. Such an approach would be in line with the elegant work from the Modeling of 


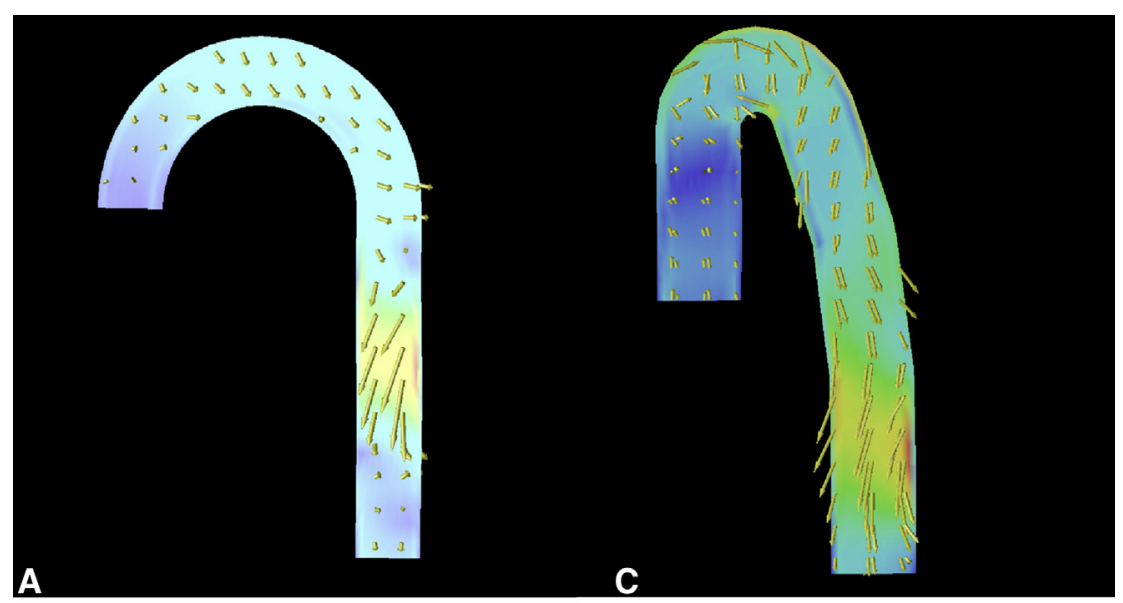

B

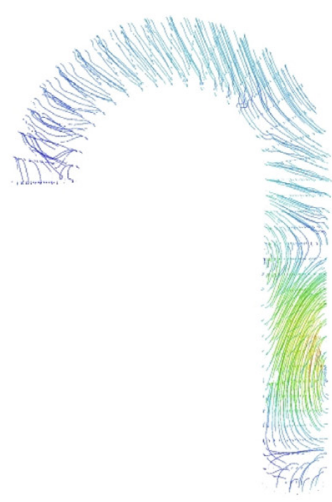

D

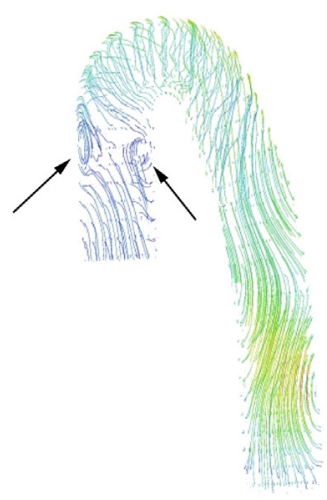

FIGURE 5. A and C, Velocity field, and (B and D) streamlines determined at the instant time $\approx 0.016$ second. A and B, Normal arch; C and D, gothic arch. Note the recirculation zones in the ascending aorta in the gothic arch (D, black arrows).

Congenital Heart Alliance Collaborative Group, which has used patient-specific data from MRI studies of patients after Norwood arch reconstruction to assess the distensibility of the aorta and the ventricular-vascular coupling. ${ }^{32}$ Our computational domain corresponded with that of the thoracic aorta, from the sinuses of Valsalva to the distal thoracic aorta, using geometric parameters commonly fixed in such mathematical modeling of the aorta (eg, diameter fixed $\mathrm{R}=0.5 \mathrm{~cm}$ and fixed Young modulus to $\mathrm{E}=3.106$ dynes $\left./ \mathrm{cm}^{2}\right) \cdot{ }^{19,20}$ Upstream, no model is available for the heart. Downstream, no modeling is available for the subdiaphragmatic vascular bed. This presents the advantage that our results are independent from possible biologic variability in the upstream or downstream region. However, we acknowledge that our computations are not reliable from the point at which the pressure pulse reaches the end of the domain. Additionally, our computation considered only 1 pressure pulse wave in all geometries. The state at the end of our simulation was quite different from the state at the beginning; thus, the flow in our model was not periodical. No model is available for understanding the processes of adaptation to the physiologic conditions, such as ventricular hypertrophy or wall thickening. This would require additional complex and iterative modeling for longer periods.

An incompressible newtonian fluid is characterized by 2 parameters only: viscosity and density. The artery, considered as elastic, has a Young modulus and a Poisson coefficient. Detailed values of these material properties are not well known owing to the difficulty in performing measurements in vivo and matching the results to simplified models. Thus, we chose commonly used values for these parameters, available in the published data of numeric simulation of blood flow. ${ }^{15}$ We did, however, incorporate vessel compliance in our model, because this was a key factor to provide more realistic values for indexes of WSS compared with simulations assuming rigid wall behavior. ${ }^{13,14}$

\section{Clinical Perspectives}

Notwithstanding the limitations imposed by the mathematical modeling of the aortic arch geometry and its consequences, the model has produced findings that provide potentially important insights into the fluid dynamics and aortic biomechanics in these 2 types of aortic arch, "gothic" and "Romanesque." To assess the clinical relevance, we compared the predictions of the model with the 

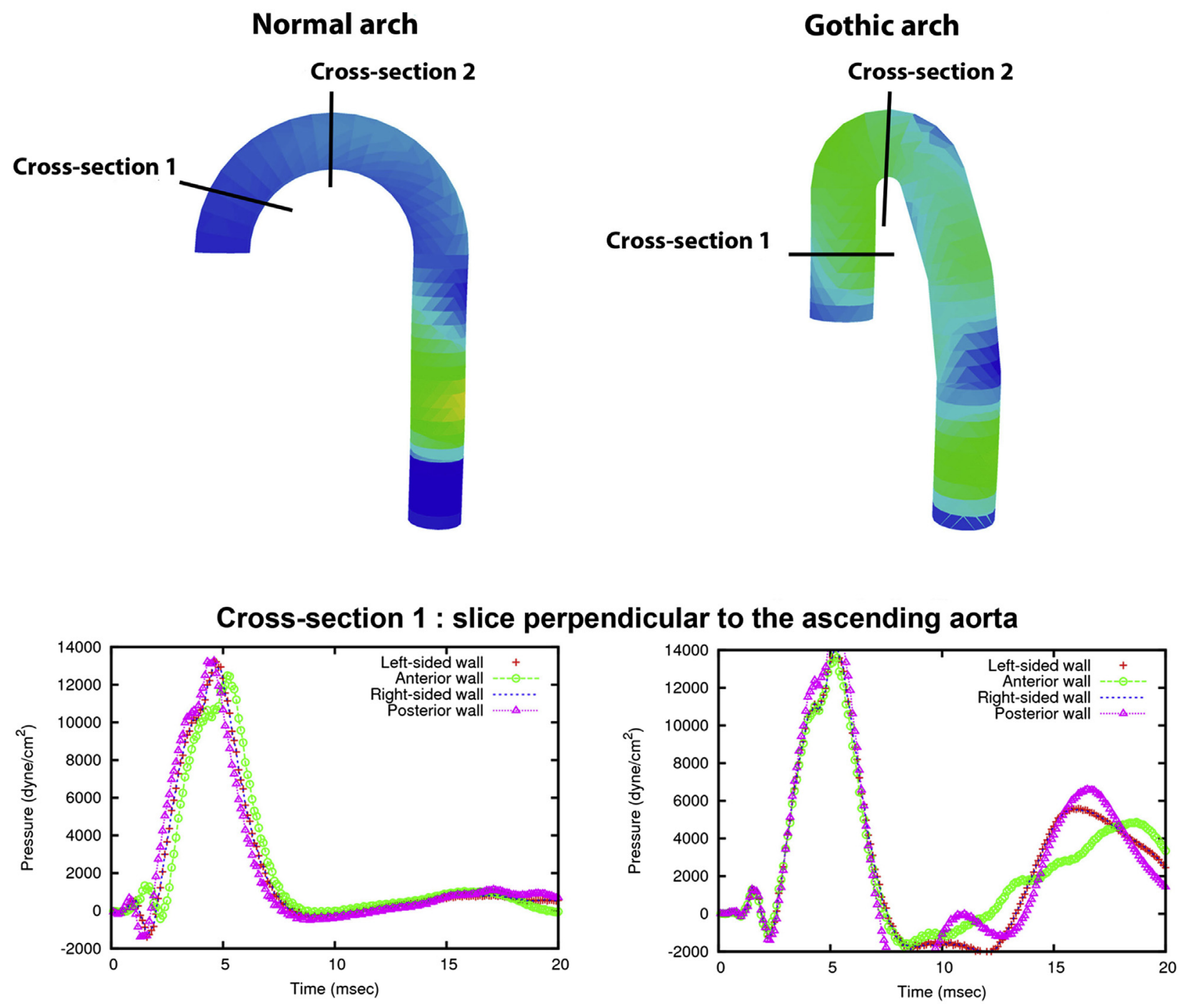

Cross-section 2 : slice perpendicular to the horizontal aorta
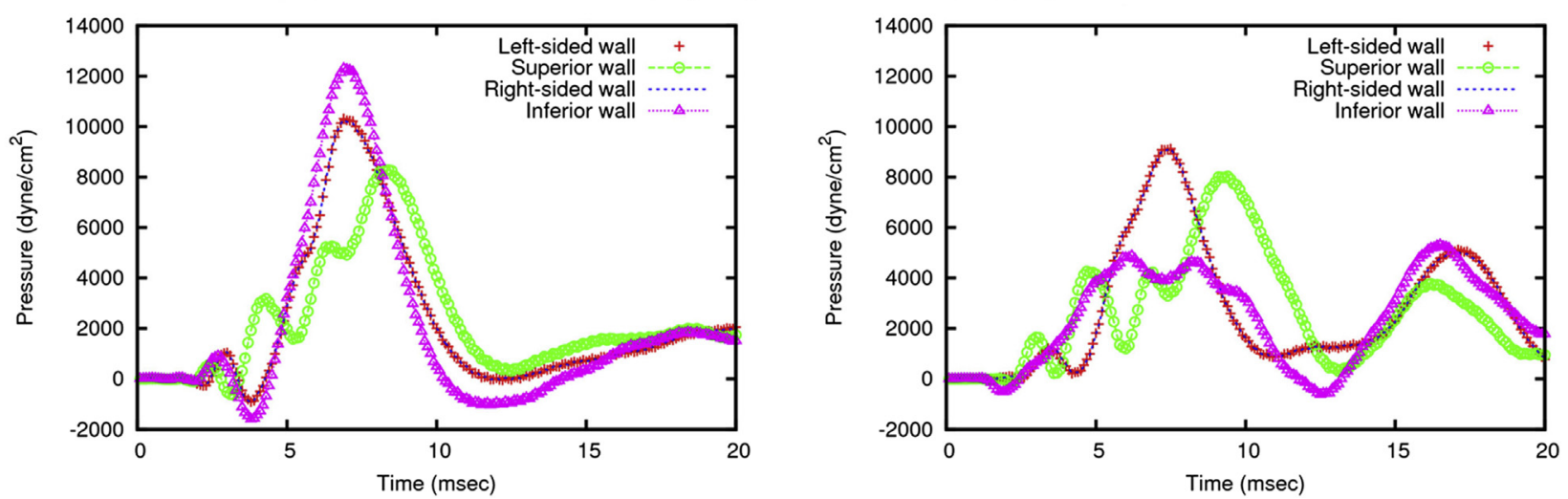

FIGURE 6. Pressure wave propagation. Top, Drawings highlighting the moment when the pressure wave reaches the descending aorta (time $\sim 0.016$ second) in the normal and gothic arch. Colors denote pressure values, from smallest (blue) to largest (yellow). Cross-section 1, pressure magnitude plotted against time at 4 points located at the anterior, posterior, and left and right wall in a cross section of the ascending aorta. Cross-section 2, pressure magnitude plotted against time at 4 points located at the superior, inferior, and left and right wall in a cross section of the horizontal aorta. 

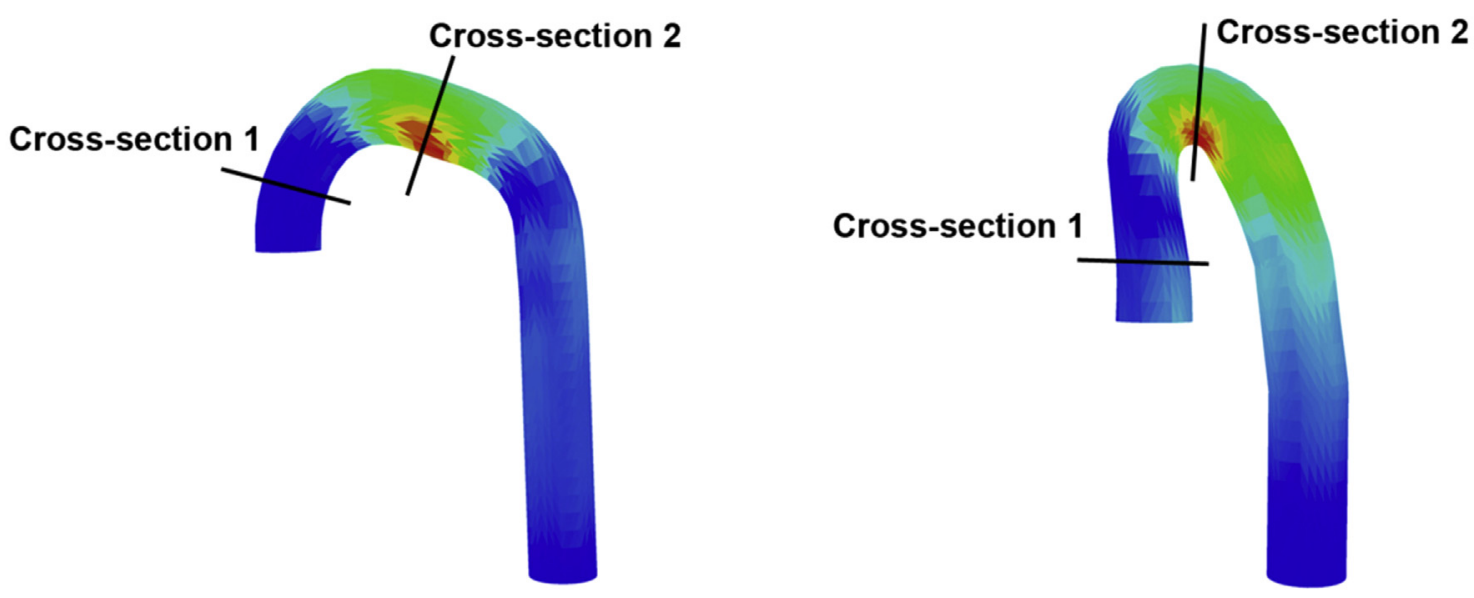

Cross-section 1: slice perpendicular to the ascending aorta


Cross-section 2 : slice perpendicular to the horizontal aorta
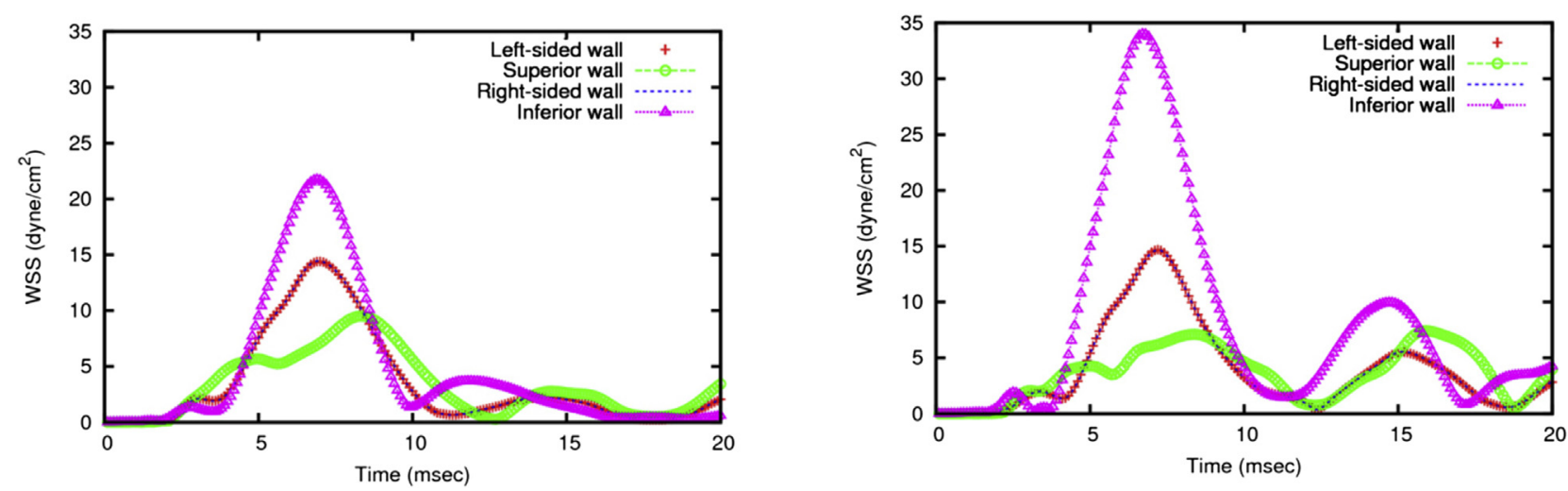

FIGURE 7. Wall shear stress (WSS) mapping and magnitude. Top, WSS distribution at an instant corresponding to the passage of the pressure wave (time $\approx$ 0.007 second) in the Left, normal and Right, gothic arch. Colors denote WSS values, from smallest (blue) to largest (red). Cross-section 1, magnitude of the WSS plotted against time at 4 points located at the anterior, posterior, and left and right wall in a cross section of the ascending aorta (Left, Romanesque arch; Right, gothic arch). Cross section 2, magnitude of the WSS plotted against time at 4 points located at the superior, inferior, and left and right wall in a cross section of the horizontal aorta (Left, Romanesque arch; Right, gothic arch).

actual patient images from MRI scanning and confirmed that the pattern of ascending aortic dilatation observed conformed to that predicted by the model. Ascending aortic dilatation and upper body hypertension have been wellrecognized as potentially serious complication in patients after coarctectomy, occasionally requiring medical 
treatment and, occasionally, surgical intervention. ${ }^{33}$ The gothic arch is a particular arterial phenotype leading to an increased risk of cardiovascular events, including, especially, the occurrence of hypertension on exercise and/or at rest. We have found a close relationship between the gothic arch morphology and the occurrence of eccentric dilatation of the ascending and horizontal aorta. Currently, therefore, in our routine clinical practice, we have recommended an exhaustive cardiovascular evaluation of patients presenting with a gothic arch, including the measurement of the intima-media thickness of the carotid arteries, the evaluation of the left ventricular mass and function, and the assessment of the blood pressure response to exercise. We believe that patients with a gothic arch should be seen every 1 to 2 years if increased intima-media thickening and/or eccentric dilatation of the aorta are present and every 2 years in the absence of such abnormalities. Patients with a normally smooth Romanesque arch could be evaluated less frequently in the absence of any intima-media or aortic diameters abnormalities (ie, every 2 to 3 years).

\section{CONCLUSIONS}

We have described a mathematical model useful for analyzing the relationship between the aortic arch shape and flow dynamics. Our model has demonstrated that an angulated "gothic" arch is associated with significant disturbances in blood flow, pulse wave pressure, and WSS in the ascending and horizontal aorta. Numeric simulations can explain the pathophysiologic relation between the "gothic" arch and the increase in blood pressure in the ascending aorta that had been previously observed in patients after coarctation repair. ${ }^{1,2}$ Furthermore, we have described the pattern of eccentric enlargement of the ascending aorta that can be expected in this situation, which should inform imaging protocols and interpretation for such patients.

\section{References}

1. Ou P, Bonnet D, Auriacombe L, Pedroni E, Balleux F, Sidi D, et al. Late systemic hypertension and aortic arch geometry after successful repair of coarctation of the aorta. Eur Heart J. 2004;25:1853-9.

2. Ou P, Mousseaux E, Celermajer DS, Pedroni E, Vouhe P, Sidi D, et al. Aortic arch deformation following coarctation surgery: effect on blood pressure response. $J$ Thorac Cardiovasc Surg. 2006;132:1105-11.

3. Clarkson PM, Nicholson MR, Barratt-Boyes BG, Neutze JM, Whitlock RM. Results after repair of coarctation of the aorta beyond infancy: a 10 to 28 year follow-up with particular reference to late systemic hypertension. Am J Cardiol. 1983;51:1481-8.

4. Simsolo R, Grunfeld B, Gimenez M, Lopez M, Berri G, Becú L, et al. Long-term systemic hypertension in children after successful repair of coarctation of the aorta. Am Heart J. 1988;115:1268-73.

5. LaDisa JF Jr, Dholakia RJ, Figueroa CA, Vignon-Clementel IE, Chan FP, Samyn MM, et al. Computational simulations demonstrate altered wall shear stress in aortic coarctation patients treated by resection with end-to-end anastomosis. Congenit Heart Dis. 2011;6:432-43.

6. LaDisa JF Jr, Alberto Figueroa C, Vignon-Clementel IE, Kim HJ, Xiao N, Ellwein LM, et al. Computational simulations for aortic coarctation: representative results from a sampling of patients. J Biomech Eng. 2011;133: 091008.
7. Menon A, Wendell DC, Wang H, Eddinger TJ, Toth JM, Dholakia RJ, et al. A coupled experimental and computational approach to quantify deleterious hemodynamics, vascular alterations, and mechanisms of long-term morbidity in response to aortic coarctation. J Pharmacol Toxicol Methods. 2012;65:18-28.

8. Olivieri LJ, de Zélicourt DA, Haggerty CM, Ratnayaka K, Cross RR, Yoganathan AP. Hemodynamic modeling of surgically repaired coarctation of the aorta. Cardiovasc Eng Technol. 2011;2:288-95.

9. Roos-Hesselink JW, Schölzel BE, Heijdra RJ, Spitaels SE, Meijboom FJ, Boersma E, et al. Aortic valve and aortic arch pathology after coarctation repair. Heart. 2003;89:1074-7.

10. Pisano C, Maresi E, Balistreri CR, Candore G, Merlo D, Fattouch K, et al. Histological and genetic studies in patients with bicuspid aortic valve and ascending aorta complications. Intract Cardiovasc Thorac Surg. 2012;14:300-6.

11. De Caro E, Trocchio G, Smeraldi A, Calevo MG, Pongiglione G. Aortic arch geometry and exercise-induced hypertension in aortic coarctation. Am J Cardiol. 2007;99:1284-7.

12. Martins JD, Thomas B, Tavares NJ, Pinto FF. Aortic arch geometry after aortic coarctation repair: systematic magnetic resonance study in a consecutive series of patients. Rev Port Cardiol. 2012;31:403-4.

13. Figueroa CA, Vignon-Clementel IE, Jansen KC, Hughes TJR, Taylor CA. A coupled momentum method for modeling blood flow in three-dimensional deformable arteries. Comput Methods Appl Mech Eng. 2006;195:5685-706.

14. Ladisa JF Jr, Taylor CA, Feinstein JA. Aortic coarctation: recent developments in experimental and computational methods to assess treatments for this simple condition. Prog Pediatr Cardiol. 2010;30:45-9.

15. Quarteroni A, Formaggia L. Modelling of living systems. In: Ciarlet PG, Lions JL, eds. Mathematical Modelling and Numerical Simulation of the Cardiovascular System. Handbook of Numerical Analysis Series. Amsterdam: Elsevier; 2004:3-127.

16. McDonald DA. Contours of pressure and flow waves in arteries. In: Nichols WW, O'Rourke MF, eds. Blood Flow in Arteries. 3rd ed. London: Edward Arnold Ltd; 1990

17. Fung YC. The flow properties of blood. In: Fung YC, ed. Biomechanics: Mechanical Properties of Living Tissues. New York: Springer-Verlag; 1993:321-84.

18. Ciarlet PG. Volume 1: Three-Dimensional Elasticity. Amsterdam: NorthHolland; 1988:3-255. Ciarlet PG, ed. Mathematical Elasticity.

19. Fernández MA, Moubachir MA. Newton method using exact jacobians for solving fluid-structure coupling. Computers Structures. 2005;83:127-42.

20. Fernández MA, Gerbeau JF. Algorithms for fluid-structure interaction problems. In: Formaggia L, Quarteroni A, Veneziani A, eds. Cardiovascular Mathematics Modelling, Simulation and Applications, vol. 1. Berlin: Springer-Verlag; 2009. 307-46.

21. Pedley TJ. Mathematical modelling of arterial fluid dynamics. J Eng Math. 2003 47:419-44.

22. Taylor CA, Cheng CP, Espinosa LA, Tang BT, Parker D, Herfkens RJ. In vivo quantification of blood flow and wall shear stress in the human abdominal aorta during lower limb exercise. Ann Biomed Eng. 2002;30:402-8.

23. Malek AM, Alper SL, Izumo S. Hemodynamic shear stress and its role in atherosclerosis. JAMA. 1999;282:2035-42.

24. Zarins C, Giddens D, Bharadvaj B, Sottiurai V, Mabon R, Glagov S. Carotid bifurcation atherosclerosis: quantitative correlation of plaque localization with flow velocity profiles and wall shear stress. Circ Res. 1983;53:502-14.

25. Kamiya A, Togawa T. Adaptive regulation of wall shear stress to flow change in the canine carotid artery. Am J Physiol. 1980;239:H14-21.

26. Frydrychowicz A, Berger A, Russe MF, Stalder AF, Harloff A, Dittrich S, et al Time-resolved magnetic resonance angiography and flow-sensitive 4-dimensional magnetic resonance imaging at 3 Tesla for blood flow and wall shear stress analysis. J Thorac Cardiovasc Surg. 2008;136:400-7.

27. Bieging ET, Frydrychowicz A, Wentland A, Landgraf BR, Johnson KM Wieben $\mathrm{O}$, et al. In vivo three-dimensional MR wall shear stress estimation in ascending aortic dilatation. J Magn Reson Imaging. 2011;33:589-97.

28. Nordmeyer S, Riesenkampff E, Messroghli D, Kropf S, Nordmeyer J, Berger F, et al. Four-dimensional velocity-encoded magnetic resonance imaging improves blood flow quantification in patients with complex accelerated flow. J Magn Reson Imaging. 2013;37:208-16.

29. Ou P, Celermajer DS, Mousseaux E, Giron A, Aggoun Y, Szezepanski I, et al. Vascular remodeling after "successful" repair of coarctation: impact of aortic arch geometry. J Am Coll Cardiol. 2007;49:883-90.

30. Ou P, Celermajer DS, Raisky O, Jolivet O, Buyens F, Herment A, et al. Angular (gothic) aortic arch leads to enhanced systolic wave reflection, central aortic 
stiffness and increased left ventricular mass late after aortic coarctation repair: evaluation with MR flow mapping. J Thorac Cardiovasc Surg. 2008;135:62-8.

31. Leuprecht A, Kozerke S, Boesiger P, Perktold K. Blood flow in the human ascending aorta: a combined MRI and CFD study. J Eng Math. 2003;47:387-404.

32. Biglino G, Schievano S, Steeden JA, Ntsinjana H, Baker C, Khambadkone S, et al. Reduced ascending aorta distensibility relates to adverse ventricular mechanics in patients with hypoplastic left heart syndrome: noninvasive study using wave intensity analysis. J Thorac Cardiovasc Surg. 2012;144: 1307-13.

33. Cozijnsen L, Braam RL, Waalewijn RA, Schepens MA, Loeys BL, van Oosterhout MF, et al. What is new in dilatation of the ascending aorta? Review of current literature and practical advice for cardiologist. Circulation. 2011;123:924-8. 